\title{
Dairy Farm Record Keeping with Emphasis on its Importance, Methods, Types, and Status in Some Countries
}

\author{
Waktole Yadeta $^{1 *}$, Dessalew Habte ${ }^{2}$, Nebiyu Kassa ${ }^{3}$, Bethel befekadu ${ }^{2}$, Eyerusalem Fetene ${ }^{2}$ \\ ${ }^{1}$ School of Veterinary Medicine, College of Agriculture and Veterinary Medicine, Jimma University, Jimma, \\ Ethiopia \\ ${ }^{2}$ College of Veterinary Medicine and Agriculture, Addis Ababa University, \\ Bishoftu, Ethiopia \\ ${ }^{3}$ National Animal Health Diagnostic and Investigation Center (NAHDIC), Sebeta, Ethiopia
}

*Corresponding Author: Waktole Yadeta, School of Veterinary Medicine, College of Agriculture and Veterinary Medicine, Jimma University, Jimma, Ethiopia.

\begin{abstract}
A dairy farm record is a document or a file used to keep account of different activities, events, and materials regarding the farm operations, while record keeping is documenting or writing those activities on a recording materials or machines. Record keeping is a necessary element of good livestock business management. It is kept for assisting in financial planning decisions, providing data for government administrative and extension purposes, assisting in livestock management decisions, and evaluating overall activities of the dairy farm. Common types of records in dairy farm are records of Identification of cattle, financial records, production records, health records, record of agricultural inputs, records of animal feeds, daily farm records, records of farm implements and equipment, Workers and vehicle records. A basic manual (hand) record-keeping and computerized system are the two methods of record keeping in dairy farm. Decision-making in dairy farm can be greatly enhanced by analyzing both production and financial records and their impact on profitability. The first officially recognized recording system in dairy farm was started when milk recording organizations were formed in Denmark in 1895. The recording movement spread rapidly and now plays an important role in all countries with an advanced dairy industry. Illiteracy and low numeracy levels, lack of time, lack of incentive, and lack of awareness are major constraints faced by farmers in developing countries to keep dairy records. Although there are many dairy farms in the world that practice different types of record keeping, there are few literatures available that explain the magnitude and status of dairy farm record keeping. Therefore, Status of dairy farm record keeping should be identified by researches, government and non-governmental organizations should be involved in improving awareness on record keeping in dairy farms and academicians and researchers should give focus to do researches on dairy cow record keeping.
\end{abstract}

Keywords: Dairy farm, Record keeping, Types, Methods, Status

\section{INTRODUCTION}

A dairy farm record is a document or a file that is used to keep account of different activities, events, and materials regarding the farm operations, while record keeping is documenting or writing those activities on a recording materials or machines [1].

Record keeping is a necessary element of good livestock business management. It is kept for assisting in financial planning decisions, providing data for government administrative and extension purposes, assisting in livestock management decisions, and evaluating overall activities of the dairy farm [2].

There are different types of dairy farm records a farmer should keep to run a successful farm business. These are records of Identification of cattle, financial records, production records, health records, record of agricultural inputs, records of animal feeds, daily farm records, records of farm implements and equipment, Workers and vehicle records [3].

Record-keeping can be accomplished through a variety of methods, from a basic manual (hand) record-keeping method to an elaborate computerized system. Selecting these methods depends on the size of the herd, the expected use of the records, type of farms and the individuals who own the farm. 
There is no "best" record keeping system for all situations, but, at minimum, a farm records system should provide accurate and necessary information, fit into the farm organization or framework, and be available in a form to aid decision-making [4].

Evaluating dairy farm record refers to record analysis. The evaluation process allows a farm manager or owner to make informed decisions based on actual farm performance. Therefore, establishing and using an effective farm record-keeping system for an ongoing farm operation aids in farm planning, informed decision-making and analysis of both production and financial records. Once a farm recordkeeping system has been established, analyzing the records can begin. Decision-making can be greatly enhanced by analyzing both production and financial records and their impact on profitability. Appropriate analysis can be made when accurate and complete farm records are available [5].

Usefulness and leading to actions, being easy to be converted into information, simplicity, avoiding duplication as much as possible are among a criteria a good record keeping should satisfy [6].

The first officially recognized recording system in dairy farm was started when milk recording organizations were formed in Denmark in 1895. The recording movement spread rapidly and now plays an important role in all countries with an advanced dairy industry [7].

Keeping of farm records is affected by farm size, level of formal education of the owners, years of farming experience, and status of the farmer [8]. Illiteracy and low numeracy levels, lack of time, lack of incentive, and lack of awareness are major constraints faced by farmers in developing countries to keep dairy records [9].

Similar to other African countries, in Ethiopia, there is no available study that assessed the record keeping practice of the dairy farmers at a country level, except the study by [10] inShashemene-Dilla area, southern Ethiopia, which identified that About 79 and $94 \%$ of the urban and mixed crop livestock producers in the area, respectively, do not have any record keeping schemes.

Generally, although there are many dairy farms in the world that practice different types of record keeping, there are few literatures available that explain the magnitude and status of dairy farm record keeping. Therefore, the objectives of this review paper are:-

- To review the concepts and attributes of dairy farm record keeping and

- To highlight the status of dairy cow record keeping in different countries

\section{IMPORTANCE OF RECORD KEEPING IN DAIRY FARM}

Record keeping is a necessary element of good livestock business management. With no written records, farmers have to depend on their memory while making decisions regarding their farm practices. But, memories can become unreliable after a few days, months or years. The ultimate purpose of a recording system is to improve the level of herd performance by achieving things better, running the farm more competently, or reducing the possibility of poor future performances [2]. Generally, Farm records are kept for all or some of the following reasons:-

\subsection{To Assist in Financial Planning Decisions}

Financial records, in more detail can be used for cash flow planning, enterprise analysis and other purposes. Record is useful to review farming activities to determine which of ventures were the more profitable and which did not pay and should be either made more efficient or eliminated [11]. Farm managers use records to construct balance sheets, cash flow and income statements, and other financial aids for making more informed decisions. According to study in India by [12]identifying strong and weak points of business and providing basis for farm planning are the major benefits generated by proper maintenance of farm record keeping. In dairy farm, controlling labor is important part of financial decision making. This is usually a wages book recording days worked, wages paid, money owed, leave and other activities [13].

\subsection{To Provide Data for Government Administrative and Extension Purposes}

First, and most obvious use of record in most developed countries is to be in compliance with state and federal regulation and permit requirements. This is an essential requirement of record keeping but should not be the sole reason, and a record system can be designed which satisfies the receiver and is 
also useful for other purposes [2]. Some lending agencies and governmental bodies require financial and/or production records be maintained over a number of years. For example, the government farm program requires certain production and acreage records be reported and maintained by the farm owner [14]. Record-keeping hasimplications for keeping animal welfare and regulation of the welfare by government[15]. Recording give a clear report on the appropriate use of the antimicrobial product, including the dose, rates and length of treatment, and withholding periods which is crucial to combat antimicrobial resistance[4]. Increasingly, farm owners are being asked to keep records about chemical use, livestock waste applications and irrigation water use on their farmsto be in compliant with environmental regulation [14].

\subsection{To Assist in Livestock Management Decisions}

Records of individual animals and groups of animals, their production, health, feed use and other records are important in evaluating efficiencies by calculating production per cow, Production per hectare, feed cost per liter of milk, conception rate, calving interval, culling rate, and stocking rate that help to make a decision on management of the herd or individual [16]. According to [17] the benefits that farmers gained by keeping records were: knowing income, knowing expense, managing income and expense more effectively, changing saving habit, communicating more with family members, and trust more among family members.

\section{TYPES OF RECORD KEEPING IN DAIRY FARM}

There are different types of dairy farm records a farmer should keep to run a successful farm business. But a type of records kept vary from farm to farm depending on the size of the herd, farmers' preferences and the value of the record to be kept [18]. Generally, those types of records kept in dairy farm include:-

\subsection{Identification of Cattle}

Identification of dairy cattle requires preliminary planning. Animals may be identified by their name or a number depending on the preference of the owner. The obvious use of identification and records is when somebody assists in milking and the identification of an individual cow can be used to provide specific instructions about any special care needed during milking. Pure-bred animals are identified as part of a registration process which assists in breeding; in many circumstances, a premium value is placed on registered pure-bred animals [19]. Information should be recorded when it occurs. Putting this off leads to omissions and errors. A good herd recording system will include identification of each calf as soon as possible after birth. In addition to the identification name or number, the calf's birth date, its size, name and its sire and dam's names should be recorded on a simple identification record [20].

Identification systems may be either temporary or permanent. Ear tags, neck chains and ankle tags are usually temporary as they can be easily lost by an animal allowed to exercise or graze in a field. Permanent marks are those which cannot be lost and include hot brands, freeze brands, tattoos, and photographs. All identification systems have drawbacks such as the difficult application of brands and tattoos. For this reason a combination of systems may be used. Numbers allocated to individual animals may be simply consecutive, or include specific meaning for the animal, for example the number A801 might refer to the first calf born during 1998 to the sire (semen) identifying number A. Such coding is useful in large herds with multiple sires, but may not be necessary for most smallholders [21].

Tattoos may be used in animals' ears with appropriate tattoo pliers which automatically advance the number tattooed by one for each successive application. Tattoos are hard to read; reading may be assisted by holding a light behind the ear which highlights the darker tattoo. Tattooing on naturally dark skin makes tattoos particularly difficult to read [22].

Photographs and sketches may also be used for animals with distinct colouring which can be easily used by assistants who may not be familiar with individual animals on certain occasions. Brands may be either hot or freeze types. Hot branding is permanent and is easy to read but disfigures the hide of a cow. This has implications both in terms of the value attached to the hide when animals are culled, and to the appearance of the animal during its productive life [21]. 


\subsection{Financial Records}

Financial records consider total costs of production (expenditure records) including costs of equipment, land, worker's payment, farm facilities and Sales record.Sales records are used to keep a record of all sales made from farm produce. Financial records are now being used extensively in production testing programs as well as in programs for consultants and veterinarians [23]. It allow dairy producers to project what an individual cow may produce in the remainder of her lactation, and can indicate the financial results of culling her. In turn, this may indicate whether it is more profitable for the manager to cull her, keep her or cull another cow. In other cases, these records may project cash flow for the next month, year or other period of time using reasonably valid assumptions of future prices and yields [24].

\subsection{Production Records}

Production records are used to document everything that is produced on the farm. These records are kept every day and analyzed every week, month and year. Thus, there is a weekly record, a monthly record, and an annual record of everything produced on the farm. They help the farmer to keep track of how well the farm is doing. Production records are important since farmers base many of their everyday decisions on these figures.For example, dairy farmers need to know what daily production level they should not drop below before drying up a cow, so as to not waste feed and other inputs on a cow that is producing less value than she is consuming. They also need to know which cow and bull combinations result in the most productive offspring, and the optimum time to breed cattle [2].

Production record is useful to cull the least profitable cows, feed for most efficient production, make precise management decisions for greatest returns and select animals with returns and select animals with the greatest genetic producing ability for herd replacements and breeding[3].

The two most important production records in dairy farm aremilk production records, which include pounds of milk, fat percentage, protein percentage and somatic cell countand Reproductive records, which should include calving, breeding and fertility data as well as date of birth, date of all estruses or heats, breeding dates including the sire used and results of veterinary checks including pregnancy checks [25].

\subsection{Health Records}

Health records kept in dairy farm should include all vaccinations, treatments, all diseases the animal has had and the somatic cell count data from the analysis of the monthly milk records. Reasons for culling animals and problems on a specific day should also be included in the health records [3].

\subsection{Record of Agricultural Inputs}

Especially for extensive and semi-intensive dairy farm, this record is used to keep track of all agricultural inputs on the pasture such as fertilizers, seeds, minerals and etc. The record often also contains the amount of that was bought, the amount that has been used, and what is left. Keeping documentation of soil and manure nutrients, land application of nutrients, and crop yields can assist in farm management decisions that will improve profitability [2]

\subsection{Records of Animal Feeds}

This record is used for keeping an inventory of the types of animal feed and the quantity purchased, used, and also quantity in stock on a daily basis. This record will help keep a track of the amount of feed that is provided for the animals. It could be anything like the amount of supplements fed to a cow, or the total amount of concentrate fed for pasture-grazed cows, and so on. Feeding records can be utilized both for every day administration and change of the feed proportion. Together with the production information, it can, for instance be used to change the feed proportion if a milking cow requires more concentrate, or help in choices about inspecting animals which appear to not develop, but rather still eat a lot. Feeding record can be used to plan a feeding plan which tells how much feed is required everyday per creature in various age gatherings (adults, infant, pregnant the first run through and so on[26]. 


\subsection{Daily Farm Records}

These are the records of all important daily activities and events that happen on the farm. These records help the farmer keep track of past farming activities and plan for future activities. It is also useful to record unusual situations and matters in the farm [27].

\subsection{Records of Farm Implements and Equipment}

This is used to keep an inventory of all the equipment on the farm and their quantity. It can also contain the date of purchase of the equipment and sometimes their description. Especially useful to manage the equipment's in the farm in a good manner and to save from loss [28].

\subsection{Workers and Vehicle Records}

Workers record is used to keep the record of staffs. It is also known as labour record while vehicle record is a record of all vehicles used on the farm, petrol and oil used, and also any repairs and servicing and the dates of the repair or servicing [29].

\section{Methods}

Record-keeping can be accomplished through a variety of methods, from a basic manual (hand) record-keeping method to an elaborate computerized system. Selecting these methods depends on the size of the herd, the expected use of the records, type of farms and the individuals who own the farm. There is no "best" record keeping system for all situations, but, at minimum, a farm records system should provide accurate and necessary information, fit into the farm organization or framework, and be available in a form to aid decision-making [1].

\subsection{Manual (Hand System)}

A large number of hand systems are available. These are card files or individual cow record charts, tags, color coding, manuals and record books. Individual cow record chartfor each heifer or cow within the herd should be kept onfile. These records are kept in a filing tray or folder for ease of portability and fielduse. They should be kept in numerical cow identification order for ease of checking. These charts provide the dairy manager with a written history of the animal'sgrowth, health and vaccinations, breeding and sire information used, calvings, andmilk production records. Colourcoded file signals may be attached to the top of the chart to facilitate recognition of the animal's status. These signals can identify the reproductive status of cows as well as other information. A milking book should be used for a milk record and insemination book to register breeding data [30].

In a manual recording system, it is usually time consuming and tedious to find important data and to make any decisions. Thus, a farmer usually takes much effort to analyze and to use its results for further action. This system is usually applicable in small herd size farms where records can be written by hand easily [4].

\subsection{Computerized Record-Keeping System}

Historically, many farm managers have found keeping and analyzing farm records a challenge. However, a number of challenges have been addressed through computerized record-keeping systems. A computer allows the dairy producer to have management reports available for an individual cow, a group of cows or the herd. These reports then allow the quality and effectiveness of management to be improved by using information in a condensed form. These management reports should cover all areas of herd management, including production, nutrition, reproduction, inventory, replacements, financial and health [31].

Computerized record-keeping system utilizes dairy management softwares which can be categorized into threedifferent types: a simple event and record display program, afully-featured management program and an integrated management program. A simple event and record display program is designed to just keep and view the records. Whereas, the fully-featured management program, does not only keep records, but also analyzes them. While the integrated management program, is a fullfeatured management program that is incorporated with real time sensors and monitors such as milk flow meters and feeding systems. These sensors and monitors then send the information about milk production and feeding patterns of individual cows or herd to the recording system [1]. 
The dairy producer should choose a software program that best suits his/her needs. The data should allow dairy producers to determine how they compare to other dairy producers so they can determine the strong and weak points of their operation. This comparison allows dairy producers to determine the areas they can most improve in their herd management [4].

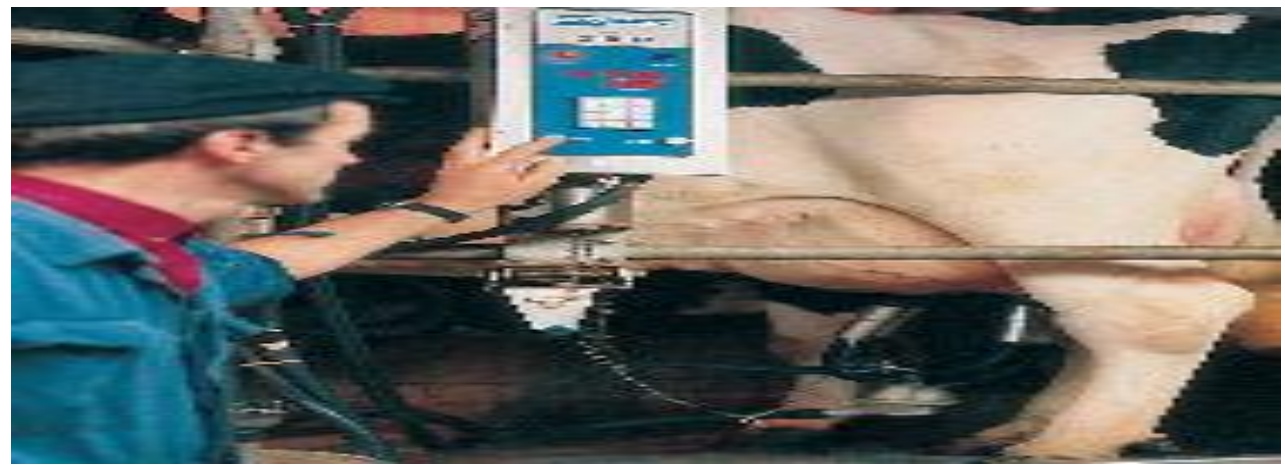

Figure1. Milking management aided by milk meter (computerized dairy farm record).

Computerized record-keeping system were developed and have been applied in large dairy farms, because it has advantages of allowing information to be summarized more easily, printing the reports more easily and handling huge data. But the utilization of a computerized recording system by small scale farmers is very rare and not given the priority.

Among the main reasons for the lack of usage are due to the cost of buying the system which is expensive, complexity of the program, and the level of computer literacy [32].

\section{DISCUSSION}

\subsection{Analysis of Dairy Farm Records}

Record analysis refers to evaluating farm records. The evaluation process allows a farm manager to make informed decisions based on actual (or projected) farm performance. Obviously, record analysis cannot take place without first keeping records. Therefore, establishing and using an effective farm record-keeping system for an ongoing farm operation aids in farm planning, informed decisionmaking and analysis of both production and financial records. Once a farm record-keeping system has been established, analyzing the records can begin. Decision-making can be greatly enhanced by analyzing both production and financial records and their impact on profitability. Appropriate analysis can be made when accurate and complete farm records are available [5].

Analysis of records is more suitable for computerized record keeping system as computers contain many software programs which include graphic displays for ease in evaluating the information and to assist in decision making. You may obtain graphs of individual cows, groups of animals within the herd or the entire herd. Graphs are not essential in a record-keeping system but are sometimes much easier to understand, evaluate and use than data tables. Breeding and health information displayed graphically quickly shows if the reproductive performance of a group of cows or an individual cow is within the goals established by the dairy producer [33].

\subsection{Criteria For Good Record Keeping In Dairy Farm}

According to[34], there are several sets of records that must be kept in dairy farm, inevitably involving much of the farmer's time. Hence, if records are not to be more trouble than they are worth, they should satisfy the following criteria:

\subsubsection{Must Be Useful and Lead to Actions Being Taken}

Unless a record is specifically intended to be used for some future action or in management planning it should not be kept. Most importantly, records must be kept up to date. Incomplete or incorrect records can be misleading and result in less than optimal decisions [6].

\subsubsection{Must Be Easily Converted into Information}

Records must be kept in such a form that they can be easily converted into information. Before keeping a record, the eventual end use must be decided upon so that the form in which the data are 
Dairy Farm Record Keeping with Emphasis on its Importance, Methods, Types and Status in Some Countries

recorded will facilitate later analysis and interpretation. Too often the end use is not considered, and the usefulness of the data is severely impaired [35].

\subsubsection{Record Keeping Systems Must Be Simple}

Dairy farmers have enough to do without burdening themselves with complex record keeping systems that are difficult to understand and time consuming to complete, and therefore nearly impossible to delegate to employees. Therefore, recording system used should be simple [6].

\subsubsection{Duplication Must be Avoided as much as Possible}

Some data may have to be recorded more than once in different forms, but this must be reduced to a minimum. In other words, if a record is to be made in the field, the recording system should be such that data can be conveniently entered in the field and does not have to be re-entered back[34].

\subsection{Factors Affecting Keeping of Dairy Farm Records}

Keeping of farm records is affected by certain factors. Farm record keeping is independent of age, gender, farm size, and level of formal education and years of farming experience [36]. The research by [8], however, further showed that there was a significant relationship between farm record keeping and farmer status, the receipt of credit and net income. Farmers who owned the larger farms tended to keep records than those with relatively smaller farms. Full-time farmers also tended to keep farm records than part-time farmers. A higher proportion of farmers who kept records had obtained credit because their farm records were used to provide an indication of the viability of the farm business in order to receive credit from financial institutions. Farmers who keep farm records are likely to have higher incomes.

\subsection{Constraints of Keeping Farm Records}

Farm record keeping is often seen as an ordinary task by farmers. Obviously, farmers are faced with constraints which cause their inability to keep farm records. The lack of keeping farm records is more pronounced due to the high levels of illiteracy and low numeracy levels in most low resource African farming communities. Another constraint faced by farmers is that, most of them engage in several enterprises and mixed farming systems, and thus farm record keeping requires much of their time. They are therefore faced with time constraints which hinder them from keeping farm records .The subsistence nature of farming does not produce any incentive for keeping the farm records. Farmers therefore cannot engage separately trained accountants for helping them in farm accounting [9].

The reason for not keeping farm record in Shashemene-Dilla area, southern Ethiopia was that the owners didn't have adequate experience and were not aware of the benefits [10]. According to study in Anand District of Gujarat, India by[12], the major reasons which lead to not keeping of farm records were: illiteracy of farmers with regard to record keeping, lack of time and lack of awareness with regard to various types of record keeping. This clearly indicates that, the lack of proper understanding regarding the record keeping types and methods unable them to maintain farm records. Lack of time in maintenance of farm records is also led by the awareness and illiteracy to record keeping. According to that study, there were significant association between the education and maintenance of farm records. As education level increases, farmers with maintained farm records were also increasing as compared to non-maintainer of farm records. The findings revealed that record keeping practices and process increase the costs of production thus affecting the performance and growth. However the study also revealed that record keeping is a vital practice in business management because it facilitates accountability process, proper management and decision making.

\subsection{Status of Dairy Farm Record Keeping in Different Countries}

The first officially recognized recording system in dairy farm was started when milk recording organizations were formed in Denmark in 1895 [7]. The recording movement spread rapidly and now plays an important role in all countries with an advanced dairy industry. In some countries (e.g. Denmark, Israel, the Netherlands, Norway and Sweden) more than 50 percent of dairy cows are recorded [37]. According to study in Anand District of Gujarat, India by[12] out of 150 total farmers studied, 50 percent have revealed not keeping any of the farm record. In central Thailand, out of 497 farms studied, Seventy eight percent of all farms did not keep farms records [38]. In Malaysia, even many small scale dairy farms still use hand written record books [4]. 
In the USA, the National Co-operative Dairy Herd Improvement Programme provides an overall testing and recording service. Information on production and management is provided to dairy farmers to assist them in improving their own herd profitability. Data is also useful to breeding groups and to universities and government research programmes. It is funded by fees charged to individual dairy farmers in the data collection process and, in its development phases over several decades relied on government funding. Dairy Herd Improvement organizations operate in 48 states, largely in the form of member co-operatives governed by dairy farmer boards [39]. The Dairy Herd Improvement organizations are represented primarily through the National Dairy Herd Improvement Association which has responsibility for interpreting and enforcing standards and monitoring the quality of services provided to members. Processing is conducted through nine major centers operated by public universities, State Dairy Herd Improvement organizations, and milk marketing co-operatives or in some cases privately owned processing centers. The system caters for around five million cows and some miscellaneous goats, representing approximately 45 per cent of the national dairy herd [19].

Like USA, Modern dairy farms in developed countries usedairy herd improvement (DHI) records, which provide information for producers to use in improving the production efficiency of their herds.

DHI records are computerized and may be maintained on a desktop personal computer (PC), on a PC with a link to a mainframe or on a mainframe only where the information is collected in written form on the farm and mailed to a location for entry into the mainframe computer [34].

Although some dairy farms in Africa practice record keeping, there is no available literature that explain the magnitude and status of record keeping in the continent. Similar to other African countries, in Ethiopia, there is no available study that assessed the record keeping practice of the dairy farmers at a country level, but according to study by [10]in Shashemene-Dilla area, southern Ethiopia, About 79 and $94 \%$ of the urban and mixed crop livestock producers, respectively, do not have any record keeping schemes.

\section{CONCLUSION AND RECOMMENDATION}

Record keeping is a necessary element of good livestock business management. It is kept for assisting in financial planning decisions, providing data for government administrative and extension purposes, assisting in livestock management decisions, and evaluating overall activities of the dairy farm. Common types of records in dairy farm are records of Identification of cattle, financial records, production records, health records, record of agricultural inputs, records of animal feeds, daily farm records, records of farm implements and equipment, Workers and vehicle records. A basic manual (hand) record-keeping and computerized system are the two methods of record keeping in dairy farm. Decision-making dairy farm can be greatly enhanced by analyzing both production and financial records and their impact on profitability. The first officially recognized recording system in dairy farm was started when milk recording organizations were formed in Denmark in 1895. The recording movement spread rapidly and now plays an important role in all countries with an advanced dairy industry. Illiteracy and low numeracy levels, lack of time, lack of incentive, and lack of awareness are major constraints faced by farmers in developing countries to keep dairy records.

Generally, although there are many dairy farms in the world that practice different types of record keeping, there are few literatures available that explain the magnitude and status of dairy farm record keeping. Based on the above conclusion, the following recommendations are forwarded:-

- Status of dairy farm record keeping should be identified by researches

- Government and non-governmental institutions should be involved in creating awareness on record keeping in dairy farms

- Academicians and researchers should give focus to do researches on dairy cow record keeping

ABBREVIATIONS

DHI

Dairy Herd Improvement

ILRI

International Livestock Research Institute

International Journal of Research Studies in Biosciences (IJRSB)

Page | 23 
Dairy Farm Record Keeping with Emphasis on its Importance, Methods, Types and Status in Some Countries

\section{REFERENCES}

[1] Veepro Holland., 2015, dairy herd administration management handbook, vepro, Netherlands.

[2] Grisham, Elisabeth., 2007. Record-keeping systems adoption by Louisiana dairy farmers, M. S. thesis, Louisiana state University., Louisiana.,

[3] McDougall, S., Compton, C.W.R. and Botha, N., 2017. Factors influencing antimicrobial prescribing by veterinarians and usage by dairy farmers in New Zealand. New Zealand veterinary journal, 65(2), pp.8492.

[4] Jeyabalan, V., 2010. Individual cow recording and analysis system for small scale dairy farmers in Malaysia. International Journal of Computer Applications, 8(11), pp.33-38.

[5] Nuthall, P.L., 2011. Farm business management: analysis of farming systems. CABI.

[6] Stewart.P.G., 2010. Dairy farm record keeping, Dairying in Kwazulu-natal,Cedara Agricultural Development Institute.

[7] Johansson, I. 1961. Genetic aspects of dairy cattle breeding. Urbana, University of Illinois Press. 259 p.

[8] Devonish, E., Pemberton, C. A., Ragbir, S., 2000. Record keeping among small farmers in Barbados,Department of Agricultural Economics and Extension, University of the West Indies, St Augustine, Trinidad and Tobago.

[9] Poggio, M., 2006. Farm Management Records, [Online] Available: www.srdc.gov.au, retrieved on $4^{\text {th }}$ November, 2018, 9:20 GMT.

[10] ILRI, A.A.E., 2008. Dairy production, processing and marketing systems of Shashemene-Dilla area, South Ethiopia. ILRI (aka ILCA and ILRAD).

[11] Gloy, Brent A., Jeffrey Hyde, and Eddy L. LaDue., 2002. Dairy farm management and long- term farm financial performance. Agricultural and Resource Economics Review 31, no. 2,233-247.

[12] Prajapati, d. R. Vahoniya and y. A. Lad., 2015., a study on status of farm record keeping practices among the farmers in anandtaluka, international journal of business and general management (4):6.

[13] Radostits, O.M., Leslie, K.E. and Fetrow, J., 1994. Herd health: food animal production medicine (No. Ed. 2). WB Saunders company.

[14] Commons, F.M., Citation, R., 2015. PB1540 Establishing and Using a Farm Financial Record-Keeping System. The University of Tennessee Agricultural Extension Service, PB1536-2M-5/95 E12-2015-00249-95, http://trace.tennessee.edu/utk_agexfinman/1.

[15] FAWC. 2011. Education, Communication and Knowledge Application in Relation to Farm Animal Welfare. Farm Animal Welfare Committee, Defra, London. Available at: https://www.gov.uk/government/uploads/system/uploads/attachment_data/file/324908/FAWCreportonedu cationcommunicationandknowledgeapplication in relation to farm animalwelfare.pdf

[16] Dematawewa, C.M.B. and Beger, P.J., 1998. Genetic and phenotypic parameters for 305-day Yield, Fertility, and Survival in Holsteins. J. Dairy Sci. 81, 2700-2709.

[17] Trang, N.N.T. and Wongsamun, C., 2013. Practices and Opinions of Farmers on Household Bookkeeping: A Case Study in Lam Thao District, PhuTho Province, Vietnam Socialist Republic. $\quad K K U \quad$ Research Journal (Graduate Studies) Humanities and Social Sciences, 1(3), pp.26-42.

[18] M.G.G. Chagunda, A.C.M. Msiska, C.B.A.Wollny, H Tchale, J .W.Banda., 2006 .An analysis of smallholder farmers' willingness to adopt dairy performance recording in Malawi. Livestock Research for Rural Development,.Livestock Research for Rural Development, 18 (5).

[19] Falvey, L. ed., 1999. Smallholder dairying in the tropics. ILRI (aka ILCA and ILRAD).

[20] De Leeuw, P.N., Omore, A., Staal, S. and Thorpe, W., 1999. Dairy production systems in the tropics. Smallholder Dairying in the Tropics (Eds. L. Falvey and C. Chantalakhana). ILRI (International Livestock Research Institute), Nairobi, Kenya, pp.19-44.

[21] Baroin, C., 2010. Livestock Property Marks in Africa. Traditional Marking Systems. A Preliminary Survey, pp.227-240.

[22] Jones, S.M., 2014. Tattooing of cattle and goats. FSA (University of Arkansas (System). Cooperative Extension Service); 4015.

[23] Bruinsma, J., 2017. World agriculture: towards 2015/2030: an FAO study. Routledge product for visualizing a data structure. U.S. Patent 6,301,579.

[24] Lehenbauer, T.W. and Oltjen, J.W., 1998. Dairy cow culling strategies: making economical culling decisions. Journal of dairy science, 81(1), pp.264-271. 
Dairy Farm Record Keeping with Emphasis on its Importance, Methods, Types and Status in Some Countries

[25] McDougall, S. and Compton, C.W.R., 2006. Reproductive performance in the subsequent lactation of dairy cows previously treated for failure to be detected in oestrus. New Zealand veterinary journal, 54(3), pp.132-140.

[26] Bartlett, P.C., Miller, G.Y., Anderson, C.R. and Kirk, J.H., 1990. Milk production and somatic cell count in Michigan dairy herds. Journal of Dairy Science, 73(10), pp.2794-2800.

[27] Lazarus, W.F., Streeter, D. and Jofre-Giraudo, E., 1990. Management information systems: impact on dairy farm profitability. Applied Economic Perspectives and Policy, 12(2), pp.267-277.

[28] Nemes, N., 2009. Comparative analysis of organic and non-organic farming systems: A critical assessment of farm profitability. Food and Agriculture Organization of the United Nations, Rome.

[29] Yeamkong, S., Koonawootrittriron, S., Elzo, M.A. and Suwanasopee, T., 2010. Effect of experience, education, record keeping, labor and decision making on monthly milk yield and revenue of dairy farms supported by a private organization in Central Thailand. Asian-Australasian Journal of Animal Sciences, 23(6), pp.814-824.

[30] Pena, Jose., 1994 "Financial Record-Keeping Software Review," Texas Agricultural Extension Service Bulletin B-5089, Texas A\&M University System, May.

[31] Pietersma, D., Lacroix, R. and Wade, K.M., 1998. A framework for the development of computerized management and control systems for use in dairy farming. Journal of dairy science, 81(11), pp.2962-2972.

[32] Alvarez, J. and Nuthall, P., 2006. Adoption of computer based information systems: The case of dairy farmers in Canterbury, NZ, and Florida, Uruguay. Computers and Electronics in Agriculture, 50(1), pp.48-60.

[33] Becker, B.G., Graphics Properties Holdings Inc, 2001. Method, system, and computer program.

[34] 34.Tomaszewski, M.A., 1993. Record-keeping systems and control of data flow and information retrieval to manage large high producing herds. Journal of dairy science, 76(10), pp.3188-3194.

[35] Shepherd, E. and Yeo, G., 2003. Managing records: a handbook of principles and practice. Facetpublishing.

[36] Tham-Agyekum, E.K., 2010. Assessing farm record keeping behaviour among small-scale poultry farmers in the Ga East Municipality.

[37] Mcdowell, R.E. 1972. Improvement of livestock production in warm climates. San Francisco, W.H. Freeman. $711 \mathrm{p}$.

[38] Yeamkong, S., Koonawootrittriron, S., Elzo, M.A. and Suwanasopee, T., 2010. Effect of experience, education, record keeping, labor and decision making on monthly milk yield and revenue of dairy farms supported by a private organization in Central Thailand. Asian-Australasian Journal of Animal Sciences, 23(6), pp.814-824.

[39] Weimar, Mark R. and Don P. Blayney., 1994. Landmarks in the U.S. Dairy Industry. USDA, ERS, Agriculture Information Bulletin Number 694, NAL call number 1 Ag84Ab no. 694

Citation: Waktole Yadeta, et.al, "Dairy Farm Record Keeping with Emphasis on its Importance, Methods, Types and Status in Some Countries", International Journal of Research Studies in Biosciences, 8(4), pp. 1625. DOI: http://dx.doi.org/10.20431/2349-0365.0804003

Copyright: (c) 2020 Authors, This is an open-access article distributed under the terms of the Creative Commons Attribution License, which permits unrestricted use, distribution, and reproduction in any medium, provided the original author and source are credited. 